\title{
METAMORFOSIS DE LA LEGALIDAD FORMA Y DESTINO DE UN IDEAL DIECIOCHESCO
}

\author{
BERnaRdino Bravo LIRA \\ Profesor de Historia del Derecha
}

Sumario. 1. Metamorfosis de la legalidad. 2. La ley-protección. 3. La ley-garantia. 4. La ley-mandato uniforme. 5. La ley-privilegio. 6. Elementos configuradores de la legalidad contemporánea. 7. Conclusión.

Uno de los rasgos tominantes en la vida jurldica de Europa continental y de Hispanoamérica durante los dos últimos siglos es el auge de la legislación. En contraste con lo que ocurre entre los pueglos anglosajones, la ley se ha transformado en la principal fuente del derecho. Trente a ella, la costumbre y la jurisprudencia han perdido casi toda significación. El predominio del derecho legislado es hoy tan completo, que apenas podemos concebir un derecho consuetudinario o un derecho de juristas.

En estas condiciones, es mny natural que nos preguntemos cómo se produjo este auge del derecho legislato.

La respuesta a esta cuestión nos obliga a considerar las sucesivas etapas históricas a través de las cuales la ley ha conquistado el lugar preponderante que hoy tiene entre las fuentes del derecho.

En términos generales puede decirse que el auge de la legislación en Europa continental y en Hispanoamérica comienza en la segunda mitad del siglo xvir. Desde entonces hasta ahora cabe distinguir cuatro formas distintas de Iegalidad, es decir, cuatro formas de entender el cometido de la ley.

\section{META M ORF OSIS DE LA L T GALI DA D}

En primer término, encontramos la ley-protección o legalidad gubernativa. En seguida, Ia ley-garantía o legalidad estatal. En tercer lugar, la ley-mandato uniforme o legalidad general. $Y$, por último, la ley-privilegio o legalidad colectiva. 
Estas cuatro formas de iegalidad se han sucedido aproximadamente cada medio siglo. Así, la ley-protección corresponde en líneas ge nerales al período comprendido entre los años 60 del siglo xvin y la primera década del siglo xix. La ley-garantia, el periodo que inclaye desde los años 20 hasta los años 60 del siglo $x I x$. La ley-mandato uniforme, al período que se extiende desde los años 70 del siglo pasa do a los años 30 del presente siglo. Y la ley-privilegio, al período que se inicia en los años 30 de la actual centuria.

Naturalmente, estas variaciones en el cometido que se asigna a la legalidad no se producen de modo súbito. Tampoco son tan radicales como para impedir que la forma más reciente contenga en parte a la que le antecede, a la vez que se distingue, también en parte, de ella.

Así, pues, estas cuatro formas sucesivas de legalidad están cncadenadas entre sí. En este sentido, puede muy bien liablarse de fases o etapas de la legalidad. Estamos pues, ante un proceso de metamor fosis de la legalidad en la que las imnovaciones de una época son apenas algo más que esfuerzos por hacer realidad las exigencias o ideales surgidos en la época anterior ${ }^{1}$.

En otras palabras, la legalidad gubernativa que corresponde al absolutismo ilustrado de la segunda mitad del siglo xvin abre camino y permanece englobada dentro de la legalidad estatal de la primera fase del Esta to constitucional en el perfodo que abarca desde los años 20 a los años 60 del siglo xix. De un modo semejante, esta legalidad estatal, prepara y persiste dentro de la legalidad general de la segunda fase del Estado Constitucional, entre los años 60 del siglo pa. sado y los años 20 del siglo actual y, a su vez, esta legalidad general prepara la legalidad colectiva de nuestro tiempo, que se superpone a ella ${ }^{2}$.

${ }^{1}$ Sobre esta metamorfosis de la legalidad, ver Bravo Lira Bernardino, Los estudios sobre la Judicatura chilena de los siglos $\mathrm{xIx}$ y $\mathbf{x x}$, en Revista de Derecho Público 19-20, Santingo 1976, 89 ss., csp. 113 ss. El mismo, La Legalidad y sus melamorfosis, en El Mercurio, 13 noviembre 1977, resumen de al lección in $\lrcorner$ ugural del curso 1976 de Historia del Derecho en la Universidad de Chile: Metamorfosis de lu legalidad, forma y destino de un ideal dieciochesco.

${ }^{2}$ Sobre las etapas históricas del Estado constitucional, ver Bravo Lira, Bernardino, Elapas históricas del Estado constitucional en los paises de habla castellana y porluguesa (1811-19N0), en Revista de Estudios Historico-Juridicos 5 (Valparafso) 1980, 35 ss. Además, el mismo, Tres etapas 
Ahora bien, estas cuatro formas de legalidad no son sino distintas erapas de un mismo ideal. Para mostrarlo examinaremos sucesivamente cada una de ellas.

\section{I. A I, E Y P R O T E C C I $6 \mathrm{~N}$}

La primera fase de la legalidad corresponde a una ampliación de los fines del Estado más allá de lo que hasta la época del Barroco se habia entendido como debercs del monarca. Como es sabido, dichos deberes comprendían fundamentalmente mantener a los vasallos en paz y en justicia, ampararlos en la paz y en la guerra y proteger a la Iglesia, a lo cual se añadia, en los reinos americanos de la monarquia hispanoindiana, apoyar su labor evangelizadora.

Bajo el influjo de la ilustración, estos deberes del rey se transforman en fines permanentes del Estado, concebido como una institución abstracta distinta del monarca, Ademts, se añade a estos fines del Estado toda una nueva dimensión: la de crear y promover la felicidad pública. En este scntido, gobernar no se entiende ya únicamente como regir con justicia, sino también, cono desplegar una acción realizadora en busca del bien y de la prosperidad pública. En otras palabras, la justicía no es ya la suprema razón de ser del gobierno, suma y compendio de los fines del poder real, sino tan sólo una más entre las múltiples tareas que se entiende corresponden al Estado. Paralelamentc, la imagen del rey-juez, cabeza de la comunidad, cede paso a la del rey-gobernante, cabeza del Estado: primer servidor del Estado concebido como entidad abstracta, impersonal y permanente, distinta de los sucesivos titulares del poder y por ende de la persona misma del monarca?.

A esta dilatáción del ámbito de acción del Estado corresponde una transformación institucional del mismo. En función de la nueva preocupación por la felicidad pública se conforma poco a poco un

del Estado constitucional en los paises de habla castellana y portuguesa (1811) 980 ) en Revista de Legislación y Documentación en Derecho y Ciencies Sociales, año 2, No 1, Santiago. 1980, 39 ss. El mismo, Verfassungstexte bewithen wenig. Hunderte Verfassungen in Iberoamerika seit 1811 brachten nich die erhoffte stabilität en Epoche 8 (München) 1980, 25.

Bravo Lira, Bernardino, Judicatura e institucionalidad en Chile (1776. 1876): Det absolutismo ilustrado al liberalismo parlamentario, en Revista de Estudios Histórico-Juridicos $2(1976)$, 61 ss, esp. 66-67. 
conjunto de oficinas que constituyen la Administración. En otras palabras, el gobernante ya no cuenta para cumplir las tareas que le son propias tan sólo con los antiguos oficiales, sino también con un complejo cada vez más vasto de oficinas ${ }^{4}$.

Mientras la Judicatura mantiene su configuración sobre la base de oficios, la Administración se organiza solsre la base de oficinas. Su núcleo central son las secretarías del despacho o ministerios, encargadas de impulsar y dirigir desde arriba la gestión de las demás oficinas. Dentro de estas oficinas, los empleados se desempeñan bajo la inmediata dependencia de un superior jerárquico, a diferencia de los antiguos oficiales que ejercían por si mismos la competencia propia de su oficio. Es decir, los empleados de oficina no tienen más atribuciones y facultades que las que corresponden a su situación dentro de la jerarquía interna y deben actuar bajo la inmediata dirección y corrección disciplinaria de sus respetivos superiores. De esta forma, toda la gestión administrativa depende en último témino, de los secretarios del despacho o ministros, quienes, a su vez, son responsables ante el monarca de las tareas que realizan las oficinas de su dependencia 5 .

'Bravo Lira Bernardino, Oficio y oficina, dos etapas en la historia del Estado indiano, en Anuario Histórico-Juridico Ecuatoriano 5 (Quito) 1980. 241 ss., esp. 258 ss.

'Bravo Lira op. cit. (notas 3 y 4). Falta un estudio de conjunto sobre la formación de la administración en España y América española. Ver Escutero, José Antonio, Los secretarios de Estado y del Despacho, 4 vol., Madrid, 1969. El mismo, Los origenes del Consejo de Ministros en España. La Junta Suprema de Estado, 2 vol., Madrid. 1979. García Gallo Alfonso, La división de competencias administrativas en España en la Edad Moderna, en Actas del in Symposium de Historia de la Administración, Madrid, 1971, 289 ss. Martínez Cardós. Josć, Estudio preliminar a Fernández Espeso, Carlos y Martínez Cardós, José, Primera Secretaria de Estado. Ministerio de Estado. Disposiciones orgánicas (1705-1936) vol. I, Madrid. 1972. Mariluz Urquijo, José María, Origenes de la burocracia rioplalense. La Secretaria del Virreinato, Buenos Aires. 1974. Martiré, Eduardo, El estatuto legal del oficial de la adininistración pública al crearse el virreinato del Rio de la Plata, en Memoria del iv Congreso Internacional de Derecho Indiano, México. 1976, 471 ss. Barrero García Ana Maria. La materia administrativa $y$ su gestión en las ordenanzas de intendencias de América, en Anuario Histórico-Juridico Ecuatoriano 6 (Quito) 1980, 113 ss. Para comparar la administración de la época ilustrada en España y América con Alemania, Maier, Hans, Dic altere deutsche Staats und Verwallungslehre (Polizeiwissenschaft), Neuwied a. R. y Berlín. 1966. 
Dentro de este contexto, surge la ley-protección, mediante la cual el monarca regula la actuación de la Administración para proteger a sus vasallos contra sus posibles abusos. Una de las realizaciones del abolutismo ilustrado es precisamente, la formación de una Administración sujeta a la legalidad.

Así cobra forma la ley-protección, es decir: protección de los derechos de los vasallos, frente a posibles abusos de los agentes del poder o de los poderosos, acordada por un monarca a quien incumbe el gobierno por la gracia de Dios.

Los principałes exponentes de esta ley-protección son las ordenanzas, reglamentos y demás legislación orgánica que regula la actuación de la Administración ${ }^{8}$.

En Chile tenemos, la regulación de la Contaduría Mayor, establecida en 1769, que es el antecedente de la actual Contraloría General de la República?.

Las disposiciones relativas a la Casa de Moneda y a los Correos, incorporados a la Corona en 1772, instituciones que subsisten hasta hoy, aunque naturalmente su regulación legal ha experimentado considerables variaciones

La ordenanza de Intendentes, de 1782, cuya vigencia se extendió a Chile en 1786 y que sentó las bases de la organización provincial, tal como se mantuvo hasta la reciente regionalización, que reemplazó a los antiguos Intendentes de provincia por Intendentes regionaless.

Falta un estudio de conjunto. T n anticipo en Martiré cit. (nota 5).

'Silva Vargas, Fernando, La Co' taduria Mayor de Cuentas del Reino de Chile, en Estudios de Historia e las Instituciones Pollticas y Sociales 2 (Santiago 1967, 108 ss. Ademá, Cruchaga (Montt), Miguel, Estudio sobre la organización económica, la hacienda priblica en Chile 3 vol., Santiago, 1878-80, 2a ed. 3 vol., fadrid 1929. Además, Molina Evaristo, Bosquejo de la Hacienda Públice de chile desde la Independencia hasta la fecha, Santiago. 1898.

Falta un estudio sobre la materia. Ver Cruchaga (cit. nota 7) y Molina (cit. nota 7).

'Real Ordenanza para el establecimiento $e$ instrucción de intendentes de exercito y provincia en el Virreinato de Busenos Aires, Madrid. 1782. Su vigencia se extendió a Chile por el virrey Teodoro de Croix, según orden Lima 14 de enero de 1786, aprobada por real orden de 6 de febrero de 1787. Falta un estudio sobre la ordenanza de intendentes en Chile. Ver Cohos Noriega, Marfa Teresa, El régimen de Intendencia en el Reino de Chile. Fase de implantación (1786-1787), en Revista Chilena de Historia 
Como se ve, estamos ante una legalidad gubernativa. Con ella se inicia la separación institucional entre la Administración, sujeta al principio de la legalidad y de la consiguiente responsabllidad ante el inmediato superior jerárquico, y la Judicatura, cuyos magistrados ejercen $\sin$ subordinación alguna la competencia propia de su oficiolo.

La ley-protección representa una forma de brindar seguridad jurídica a los vasallos frente a la Administración. Precisamente, se sujeta la actuación gubernativa a la legalidad para impedir sus posibies busos en contra de los vasallos.

$$
\text { 111. I. A I. E Y G A R A N T I A }
$$

La segunda fase de la legalidad corresponde al primer estadio del Estado Constitucional, que en Chile se extiende en términos generales desde 1818 hasta $1860^{11}$.

del Derecho 7 (Santiago) 1978, 91 ss., y sobre algunos aspectos judiciakes. Ia misma. Institución del Juez de Campo in el Reino de chile duranle el siglo xvilı, en Revista de Estudios Histórico-Juridicos 5 (1980), 85 ss. Sobre la ordenanza en el resto de América. Sanz, Luis Santiago, El proyecto de extinción del régimen de las intendencias de Anérica y la orde. nanza general de 1803, en Revista del Insitituto de Historia del Derecho 5 (Bucnos Aircs) 1953; Comadrán, Jorge, La Real Ordenanza de Intcndentes del Rio de la Plata, en Anuario de Estudios Americanos 11 (Sevilla) 1954; Meade Esteva, Mercedes, La Intendencia en San Luis de Potosi, San Luis Potosí, 1956. Lyuch John, Spanish colonial Administration (I782-1810). The Intendant System in the Viceroyalty of the Rio de la Plata, Londres. 1958. hay trad. castellana. Bucnos Aires. 1967. Navargo Gatcia, Luis, Intendencias en Indias, Sevilla. 1959. Zorraquín Becú, Ricardo, La organización politica argentina en el periodo hispánico, Buenos Aires. 1959 (2a ed. 1967): Somayoa Guevara, Héctor Humberto, La implantación del régimen de In. tendencias en Guatemala, Guatemala. 1960; Deustua Pimentel, Carlos, Las Intendencias en el Perú 1790-1796, Sevilla. 1965. Morazzani de Pérez Enciso. Gisela, La Intendencia en Esparia y América, Calacas. 1966. La misma, Las ordenanzas de intendencias de Indias, cuadro para su estudio, Caracas. 1972. Fisher, Lillian Estelle, The Intendant System in Spanish America. Nueva York. 1969. Rees Jones, Ricardo, El despotismo ilustrado y los intendentes de la Nueva España, México. 1979.

"Bravo Lira, op. cit. (nota 3) esp. 72 ss.

"Bravo Lira, Etapas hislóricas. cit. (nota 2), 57 ss. El mimo, Portales y la consolidación del Estado constitucional en Chile, en Revista Universitaria 2 (Santiago) 1980. 122 ss. 
Con el constitucionalismo se amplia el ámbito de la legalidad. Se pasa de la legalidad gubernativa a la legalidad estatal. El imperativo fundamental es regular la acción del Estado para garantizar frente a él los derechos de los gobernados.

Esta nueva forma de legalidad pretende substituir el gobierno de los hombres por el imperio de la ley. De ahi que se contrapongan Derecho público y Derecho privado, como dos órdenes distintos sujétos a una regulación completamente diversa. Mientras en el Derecho público, que abarca la actuación del Estado, sólo puede hacerse lo que la ley autoriza, en el Derecho privado, que abarca la actuación de los individuos, puede hacerse todo lo que la ley no prohiba.

Se configura así la ley-garantia, o sea: garantia de la libertad individual frente a la arbitrariedad del Estado, establecida desde arriba con el concurso del parlamento, por gobernantes identificados con los fines permanentes del Estado, que actúan en nombre de Dios y de la Patria.

La ley-garantia es sinónimo de ley parlamentaria, esto es, aprobada con intervención del parlamento. Esta ley parlamentaria pasa a ser única forma de legislación ${ }^{12}$.

Por eso esta etapa es inseparable de la implantación del parlámento, cuya razón de ser está ligada al reinado de la nueva legalidad estatal. En efecto, al parlamento le corresponde la doble misión de concurrir a ia elaboración de las leyes y de velar por que la actilia. ción del gobierno se mantenga dentro de los marcos de la legalidad.

Pero tal vez lo más decisivo es la extensión de la legalidad a la Judicatura, cuya jurisdicción se reduce únicamente a materias civiles y criminales, con exclusión de los asuntos de gobierno. En este sentjdo es significativa la adopción de la designación Poder Judicial. En cuanto se considera a la Judicatura como un poder y no como una autoridad, se le aplica una regulación restrictiva, análoga a la que se establece para el gobierno y el parlamento. También, los jueces deben ajustar sus sentencias al principio de la legalidad. Lo cual se impone paulatinamente a través de diversas reformas, tales como: la supresión de las judicaturas especiales ${ }^{2 *}$, la supresion de los recursos

¿Bravo Lira, Etapas históricas, 56 \$s.

ssalta un estudio sobre esta materia. Ver, Ballesteros, Manuel Egidio, La lei de organización i atribuciones de los Tribunales de Chile. Antece. dentes, Concordancia i aplicación práctica de sus disposiciones, 2 vol., San. tiago. 1890; Fuentes Concha, Manuel, Historia de la Justicia Militar en 
extraordinarios de suplicación y de injusticia notoria ${ }^{14}$, la exigencia de fundamentar las sentencias, cuyo verdadero sentido lo fija la res. puesta del fiscal de la Corte Suprema Mariano Egaña a la consulta de ese tribunal15, y la regulación legal de la prueba ${ }^{16}$.

La principal expresión de esta legalidad estatal es la constitución escrita y sus leyes complementarias. En la constitución se contemplan las garantías individuales, se establece el reinado de la ley parlamentaria y se fija un catálogo de materias que sólo pueden regılarse por ley.

Lo dicho basta para mostrar que la ley-garantía representa no sólo una nueva fase de la legalidad, sino ante todo una nueva forma de brindar seguridad jurídica. Tal es al menos la razón de ser de la enunciación de las garantías individuales en la constitución, que, en último término, pretenden poner un límite a la actuación del Estado en favor de los gobernados. Tal es también, la razón de ser de la ley parlamentaria, que exige el concurso de los miembros del parlamento para la aprobación de las leyes. Tal es, igualmente, la razón

chile. Santiago. 1953; Riveaux Viltalobos, Sergio, La fusticia comercial en el Reino de Chile. Notas para su estudio, Santiago. 1955; Maffei Belloni, Jaime, Estudio de la organización judicial en Chile desde el primer Congreso Nacional hasta la dictacion de la Ley Orgdnica de Tribunales de 1875, Santiago. 1965; Bravo Lira, op. cit. (nota \$). E1 mismo, Los Estudios... (nota 1) . El mismo, Bello y la Judicatüra II. La reforma judicial, en Revista Chilena de Historia del Derecho 9 (en prensa).

1'Reglamento de Administración de Justicia de-2 junio de 1824 , en Boletin de las Leyes $y$ de las ordenes y decretos del Gobierno 1, 27, 19 junio 1824.

${ }^{16}$ Decreto 2 febrero de 1837 sobre fundamentación de las sentencias, en El Araucano 385, Santiago, 3 febrero 1897. Cfr. Consulta de la Corte Sthprema, de 11 de febrero de 1837, en El Araucano 340, 10 marzo 1837, Dictamen del Fiscal, 11 feprero de 1837 , y Decreto 19 de marzo de 1837. Sobre el origen de esta disposición, Bravo Lira, Bernardino, Bello y el De. recho I, La codificación procesal, comunicación al Congreso, Bello y el Derecho, celebrado en Santiago desde el 13 hasta el 17 de julio de 1981 (en prensa), esp. nota 121, donde se recoge la bibliografia disponible.

${ }^{20}$ Esta materia tampoco ha sido estudiada. Lira Argomedo, José Bernat. do, Prontuario de los Juicios, 3 vol., Santiago 1867.69, $3^{a}$ ed. 2 vol., Santiago. 1880-81. Sobre la significación de los prontuarios, Salvat Monguilot, Manuel, Los prontuarios chilenas en la primera mitad del siglo XIX, estudio y bibliografia, en Homenaje a Guillermo Feliú Cruz, Santiago. 1974. El misino, Sentido y forma de los prontuarios judiciales, en Revista de Derecho Procesal 7 (Santiago). 1974. 
de ser de Ja fijación de las materias de ley, que las excluye de una regulación establecida por el gobierno sin el consensa del parlamen. to. Tal es, en fin, la razón de ser de la regulación restrictiva de la actuación de los Tribunales de Justicia, con la que se pretenden evitar los posibjes abusos judiciales.

$$
\text { IV. I A LEY MANDATO LNIFOR ME }
$$

La tercera fase de la legalidad corresponde al segundo estadio del Estado constitucional, caracterizada por el surgimiento de los partidos politicos que se produce en Chile al finalizar los años 50 del sigio pasado. Esta etapa se extiende desde entonces hasta el colapso del régimen parlamentario en 192417 .

En este periodo el gobierno identificado con los intereses supremos y permanentes de la Patria, anterior a los partidos, cede paso al gobierno de partido a través del parlamento 18 .

Esta traniformación se produce paulatinamente entre 1860 y 1891. En el curso de ella el parlamento se transforma de guardián de la legalidad de las actuaciones gubernativas en rector del gobierno, mediante la exigencia de que el ministerio deba contar para permanecer en funciones con el respaldo de los partidos mayoritarios en el propio parlamento.

La ley pasa a ser un instrumento de estos partidos mayoritarios para imponer a la generalidad de la población sus propios idealés. Se convierte en reflejo de las mayorias parlamentarias y deja de ser un trasunto de un orden trascendente que los gobernantes deben res. petar.

De esta suerte, cobra forma la ley-mandato uniforme, es decir: mandato uniforme, impuesto desde arriba por la mayoria parlamentaria, en nombre de los ideales dominantes entre los partidos que Ia componen.

La discusión de la ley se transforma así en polémica y su aprobación en victoria o derrota de una posición partidista, cuando no en compromiso entre posiciones partidistas antagónicas.

${ }^{12}$ Bravo Lira, Etapas histórices ... cit. (nota 2), 68 ss. El mismo, Ma. nuel Montt y los ideales de la Ilustración, en Revista de Derecho Priblico 28 (Santiagu), 1980, 87 ss. esp, 89 ss.

${ }^{18}$ Bravo Lira, Elapas históricas... cit. (nota 2), p. 63 ss. El mismo, La funcid́n consultiva, un vacio sectilar dentro del régimen de gobierno en Chile 18741973, en Revista de Derecho Piblico 21.22 (1977). 
Durante este perfodo se lleva a cabo la mayor parte de la tarea codificadora, que en general permanece al margen de las controversias partidistas y de la discusión parlamentaria ${ }^{19}$. A través de ella se uniforma la Iegislación aplicable a toda la población.

Las expresiones más significativas de esta nueva forma de legalidad son precisamente las leyes discutidas en el parlamento. Entre ellas, se cuentan en Chile, la ley orgánica de Tribunales, que suprimió el fuero eclesiástico y los recursos de fuerza. Se delimitan asi la jurisdicción de la Judicatura eclesiástica y estatal, con una significativa ampliación de esta última ${ }^{20}$. Junto a esta ley están otras que imponen un matrimonio civil obligatorio ${ }^{21}$, un registro civil obligatorio 22 , un servicio militar obligatorio.

De esta suerte, llega a su apogeo la distinción entre Derecho público y Derecho privado, como dos órdenes diferentes, cuya expresión fundamental es en un caso la ley y en el otro, el contrato ${ }^{23}$.

Igualmente, llega a su apogeo la ley parlamentaria que ahora se emplea como instrumento para uniformar el régimen juridico de toda la población.

La legalidad da pues, un paso más. Amplía su ámbito regulador. Ya no regula primordialmente la actuación gubernativa, como sucedió bajo el absolutismo ilustrado. Tampoco regula primordialmente la actuación estatal, como sucedió durante el primer estadio del Es-

${ }^{10}$ Falta en Chile un estudio sobre la codificación similar al de Tau Anzoátegui, Victor, La Codificación en la Argentina (1810-1870). Mentalidad e Ideas Juridicas, Buenos Aires 1977. Sobre la codificación civil, Lira.Ur. quicta. Pedro, El Codigo Civil y su época, en Anales de la Facultad de Ciencias Juridicas y Sociales, 3a poca, vol. II, 4, Santiago 1955, p. 4 ss., ahora en El Código Civil y su época, Santiago 1956, p. 58 ss. Utimamente los trabajos de Guzmán Brito, Alejandro, Para la historia de la fijación del Derecho Civil en Chile durante la Repuiblica, I. La época de la fijación del derecho y sus divisiones, en Historia 14, Santiago. 1979, p. $\$ 15$. Sobrc la codificación procesal, Egaña Moteno, Luis Enrique, Estudio del parlamentarismo dutante el gobierno de don Federico Errdzurix Zañartus 1871-1876, Santiago. 1968. Bravo Lira, op. cit. (nota 15). Un panorama del movimiento codificador en los paises de habia castellana y portuguesa. el mismo, Prestupuesto para una codificación, en El Mercurio 4 septiembre 1977.

Maftei Belloni, cit. (nota 13) esp. 59 ss.

${ }^{2}$ Ley 17 julio 1884.

${ }^{2}$ Ley 20 enero 1883.

Bravo Lira, Bernardino, Régimen de gobierno y partidos polfticos en Chile 1924-1973, Santiago. 1978, 166. 
tado constitucional. Ahora, regula, a la vex, la actuación del Estado y la actuación de la población, para imponer a esta última un escatuto jurídico uniforme, sin consideración a la disparidad de situacio nes y condiciones existentes dentro del cuerpo social:

Al igual que las anteriores, esta nueva forma de legalidad representa tambiên una manera de brindar seguridad juridica. La ley mandato uniforme impuesta a toda la población pretende, en últinoo término, ampliar à máximo el campo de acción de la iniciativa individual, a través del contrato libremente convenido por las partes. Mientras la actuación del Estado sigue sujeca a la regulación legal, la actuación de los individuos se regula fundamentalmente a tra. vés del contrato.

\section{V、 LA L E Y F R I V I L E G I O}

Asi llegamos a la cuarta etapa de la legalidad, la ley-privilegio que se impone a partir de los años 30 delıpresente siglo. Corresponde a la tercera fase del Estado constitucional, caracterizada por la declinación del parlamento y de los partidos parlamentarios y la consiguiente aparición de regimenes de gobierno y partidos extraparlamentarios 24 .

La decadencia del parlamento afecta a las dos funciones que fueron la razón de ser de su implantación, comơ regulador de la gestión gubernativa, en la primera fase del Estado constitucional. Es decir, compromete tanto st función legislativa como su función fiscalizadora.

Frente a la ley parlamentaria cobran significación otras formas de legislación, emanadas del gobierno sin el concurso del parlamento, como son los decretos-leyes y los decjetos con fuerza de ley, Paralelamente, se transforma la antigua administración estatal debido a la proliferación de instituciones estatales y paraestazles y adquiere tales dimensiones que escapa de modo cada vez más completo a la fiscalización del parlamento, concebida para una administración bastan-

"Bravo Lira, Elapas históricas... (nota 2) p. ss, y el mismo, op. cit (nota 23) esp. p. 164 ss. Ultimamente, el mismo, La Constitución de 1980 Y la crisis del Estado constitucional en los palses de habla castellana y portuguesa (1920-1990) en Flevista de Ciencia Poltica 3 (Santiago) 1980. 5 s. 
te más reducida, como la que existió en las dos fases anteriozes cel Estado constitucional.

Pero, sin duda, lo más dęcisivo de esta decadencia del parlamento es el agotamiento del espíritu parlamentario. Se pierde la confianta en el debate y en los compromisos interpartidistas como medio de encarar y resolver los asuntos de gobierno. Se produce así la crisis de los partidos parlamentarios. Por otra parte, surge un nitevo tipo de partido político, que no aspira a entenderse con los demás, sino a imponer su propia ideologia. Tales son los partidos ideologicos, cuya meta es una nueva forma de gobierno de partido, en la cual la negociación interpartidista es reemplazada por el predominio sin contrapeso del propio partido 25 .

Paraleio a esta crisis del Estado constitúcional es el auge del movimiento asociativo entre los diversos sectores de la población. Sus manifestaciones son múltiples, pero entre ellas sobresalen las agrupaciones de carácter gremial, tales como colegios profesionales, sindicatos, asociaciones de empleados públicos, comerciantes, industriales, agxicultores y las cooperativas. Su significación no ha sido todavía debidamente apreciada. Al articularse de este modo la población dejó de ser un conjunto indiferenciado de individuos, numéricamente distintos pero con iguales derechos, y se perfiló, poco a poco, como un conglomerado de sectores y grupos, cada vez más diferenciados, también en cuanto a su régimen jurídico.

De esta suerte, se superan los moldes forzadamente individualistas del derecho codificado que, por pretender una vigencia general, estaba condenado a ignorar la disparidad real y $\sin$ cesar renovada de si. tuaciones y necesidades entre los componentes del cuerpo social.

Por encima de este derecho codificado, se configura en forma cada vez más nítida una gama de estatutos juridicos especiales, relativos a grupos, sectores e instituciones determinados. Surgen asi una Judicatura y un derecho laboral, una Judicatura y un derecho de menores, un derecho previsional, un derecho relativo a las cooperativas, a la visicnda, a salarios y sueldos minimos, a los artículos de uso y consumo habitual, a la vez que regímenes de excepción para determinados sectores, tales como el magisterio primario y secundario, trabaja. dores de la salud, personal de distintas instituciones estatales y paraestatales o de empresas públicas, así como para pequeños mineros,

\section{- Ibid.}


pequeños agricultores, pequefios industriales y artesanos, comerciantes mayoristas y minoristas, estibadores y trabajadores de puertos, ven dedores viajeros y demás ${ }^{28}$.

De este modo entran en decadencia simultáneamente: la uniformidad de la legislación ${ }^{27}$, la ley parlamentaria ${ }^{28}$ y la ley impuesta desde arriba ${ }^{2 \theta}$.

La ley uniforme se ve opacada por el auge de una legislacion diferenciada por sectores y actividades, instituciones y personas naturales ${ }^{30}$.

La ley parlamentaria se ve opacada por otras formas concurrentes de legislación, como son el decreto-ley, el decreto con fuerza de ley y las disposiciones administrativas ${ }^{31}$.

La ley impuesta se ve opacada por una legislación obtenida o exorada, reclamada por un grupo o entidad para el que tiene el carácter de conquista o reivindicación.

Tan importantes son estos tenómenos, que en 1973, a diferencia de lo ocurrido on 1924, la Junta de Gobierno al asumir el Mando Supremo no sólo reconoció la intangibilidad de la Judicatura, sino también de las conquistas sociales ${ }^{32}$.

- Bravo Lira, Bernardino, Nueva institucionalidad: medio siglo de trayectoria institucional en Chile 1924-1973, en Portada 43, Santiago 1973, hay separatum, Santiago 1974. E) mismo, op. cit, (nota 23 esp. 691 ss. U1timamente, el mismo, El movimiento asociatioo en Chile 1924.1973, en Politica I (Santiago) 1982, 31 ss.

nibid.

${ }^{5}$ Bravo Lira, op. cit. (nota 23), 95.

mbid.

- Ver nota 27.

tBravo Lira, Etapas históricas... (nota 2).

${ }^{a}$ Bando No l de la Junta Militar de Gobierno, Santiago 11 de septiembre de 1975: "Teniendo presente: 1. La gravisima crisis social y moral por la gue atraviesa el pais; 2 . La incapacidad del Gobierno para controlar el caos; 3. El constante incremento de grupos paramilitares entrenados por los partidos de la Unidad Popular, que llevarán al pueblo de Chile a una inevitable guerra civil,

las Fuerzas Ammadas y Carabineros deciden:

1.- El Presidente de la República debe proceder a la inmediata entrega de su cargo a las Fuerzas Armadas y Carabineros de Chile.

2.- Las Fuerzas Armadas y Carabineros están unidos para iniciar la histórica y responsable uisión de luchar por la liberación de la Patria y evitar que nuestro pais, caigá bajo el yugo marxista, y la restauración del orden y la institucionalidad. 
En otras palabras; durante el último medio siglo se ha configurado una nueva forma de legalidad: la ley privilegio; la ley privilegic para sectores o actividades diferenciadas o para instituciones o personas naturales determinadas, concedida a estos grupos o entidades por el gobernante, de ordinario en nombre de un conpromiso entre sus intereses y los de la población en general, con sanción parlamentaria o bien en uso de poderes que en teoría se atribuyen todavia al parlamento, pero que en el hecho el gobernante asume por st o por delegación.

La ley-privilegio sanciona asi un derecho que a falta de mejor denominación, puede muy bien llamarse colectivo, tomando este término del derecho laboral y que no pertenece ni al antiguo Derecho público ni al antiguo Derecho privado.

Estos son en grandes líneas los rasgos de la legalidad actual que, al igual que en épocas anteriores, no elimina a la legalidad uniforme del periodo inmediatamente precedente, sino que se superpone a ella.
VI. E L. E M EN TOS C O N F G U RA DOR E S
D F L A L E G A L I D A D C O N T E M P ORA N E A

Los límites de esta exposición no permiten entrar en un estudio de. tallado de los elementos conliguradores de esta legalidad contemporánea. Por eso, hemos de contentarnos con una breve alusión a los tres ya enunciados: la legislación diferenciada, la legislación extraparlamentaria y la legislación exorada 83 .

9.- Los trabajadores de Chile pueden tener la seguridad de que las conquistas sociales que han alcanzado hasta la fecha no sufrirán modifica. ciones en lo fundamental.

4.- La prensa, radiodifusoras y canales de televisión adictos a la Uni. dad Popular deben suspender sus actividades informativas a partir de este instante. De lo contrario recibirán fuego aéreo y terrestre.

5.- El pueblo de Santiago debe permaner en sus casas a fin de evitar. victimas inocentes. Firmado: Augusto Pinochet Ugarte, Comandante en Jefe del Ejército: José Toribio Merino, Comandante en Jefe de la Armada Nacional; Gustavo Leigh, Comandante en Jefe de la Fuerza Aérea de Chile; César Mendoza Durán, Director Gereral de Carabineros, Junta Militar de Gobierno, Santiago, 11 de septiembre de $1973^{\prime \prime}$.

sobobre el unánsito de la ley-regulación uniforme a la ley-privilegio, Luas Verdú, Pablo, Estado liberal de Derecho y Estado Social de Derecho, en 
Estos tres elementos son compatibles entre si. De hecho no faltan casos en que concurren simultáneamente. Un ejemplo de ello es el Decreto-Ley 406 de 19 de marzo de 1925, que estableció el Colegio de Abogadosa4. Este Decreto es, a la vez, una forma de legislación diferenciada, ya que se refiere sólo a los abogados y no a la generalidad de la población; una forma de legislación extraparlamentaria, ya que como todo decreto-ley fue dictado sólo por el gobierno, sin intervención del Congreso; y una forma de legislación exorada, ya que la iniciativa de su elaboración no surgió originalmente del gobierno, sino de un grupo de abogados preocupados por los intereses de su propia profesión.

Después de esta advertencia, podemos referirnos separadamente a cada uno de los tres elementos antedichos.

En primer lugar, tenemos la legislación diferenciada. Su auge es impresionante. Al menos así lo deja ver un estudio sobre las leyes despachadas con el concurso del parlamento en Chile, durante el período 1926-197935. Lo cual se confirma con el examen de la legislación extraparlamentaria que haremos a continuación.

Desde 1926 hasta 1973 se aprobaron en total 13.893 leyes parlamentarias. De ellas un 52\% (7.207) tiene carácter individual, es decir, son leyes de gracia. Un $40 \%$ (5.524) tiene carácter colectivo, es decir, afectan tan sólo a determinados sectores o actividades de la población, instituciones o personas naturales. $Y$ tan sólo un $8 \%$

Acta Salmanticensia, Derecho 11, 3 (Madrid) , 1955. Huber, Ernst Rudolf. Rechtstaat und Sozialstaat in der inodernen Industriegesselschaft (1962), nueva versión cn su Nationalstaat und Verfassungstaat. Studien zur Geschichte der modernen Staatsidee, Stuttgart 1965, 249 ss. Garcia Eduardo, Reflexiones sobre la ley y los principios generales de derecho en el derecho administrativo, en Revista de Administración Pública 40. Madrid 1969. 189 ss.

"Mrado Juan, Guillermo, El Colegio de thogados de Chile, cn Boletin fe Documentación en Dorecho y Ciencias Soriales año 1, No 3 (Santiago) 1977. 1 y 55. El mismo. El Movimiento de Asociación Profesional (19261928). ibid, año II, No 1, Santiago 1978 pp. 1 y 55, y el mismo Apuntes para un estudio del Colegio de Abogados, en Revista del foro, año i, No 3 (Santiago) 1979, 1955.

"Tagle Martínez, Hugo, Origen y generalidad de la ley chilena bajo el imperio de la Constitución de 1925, en Derecho y Justicia. Terceras fornadas Chilenas de Derecho Natural 1977, Santiago. 1977, 375 ss. 382 
(1.162) son de carácter general, o sea, se refieren a toda la pobla. ción 86 .

Esta proporción es bastante estable a lo largo del período. Al menos si consideramos' los 40 años en que el parlamento funciono regularmente, desde 1983 hasta 1973.

En las dos décadas iniciales, que corresponden a la estabilización del régimen de gobierno, esto es, desde 1933 hasta 1952, la proporción fue la siguiente: $51 \%(3.055)$ leyes individuales, $41 \% \quad(2.421)$ leyes privilegios, y $8 \%$ (495) leyes generales.

En cambio, en las dos décadas finales, que corresponden a la crisis y desintegración del régimen de gobierno, entre 1953 y 1973: las leyes individuales suben del $51 \%$ al $56 \%$ (3.829), las leyes privilegio bajan del $41 \%$ al $37 \%$ (2.563), y las leyes generales bajan del $8 \%$ ai $7 \%(476)$.

Es de advertir que las leyes individuales no tienen mayor importancia, porque en general no corresponden a la función gubernativa, sino en cuanto ejercitan la jurisdicción graciable. No son, pues, verdaderas leyes y no tienen de tales más que el nombre.

Sobre las formas concurrentes de legislación, que reemplazan o desplazan a la ley parlamentaria, su volumen y significación es muy considerable:

Entre 1924 y 1925 se dictan 816 Decretos Leyes. En 1932 se dictan 669 más. Lo que hace un total de $1.485^{37}$.

Por otra parte, entre 1927 y 1973 hubo más de 90 leyes de delegación de facultades al presidente. En virtud de ellas se dictó un total de 2.306 Decretos con fuerza de 1 ley ${ }^{38}$.

Asi, pues, tenemos que frente a 13.893 leyes parlamentarias hay 8.791 decretos leyes y decretos con fuerza de ley.

Pero más que cifras, importa el contenido de esta legislación extraparlamentaria. Ya en 1933 la Corte Suprema hacia ver que los decretos leyes tenían tal significación que seria vano intento el de pretender desconocer su eficacia. "Es fuerza darse a la razón-decía-

soid.

TConsejo de Estado, Recopilación de Decretos Leyes, vol. 12 y 13, San. tiago. 1925.

Ferrer Puig. Julio, Los decretos con fuerza de ley en el periodo 19241974 (inédito). Seminario sobre Institucionalidad Chilena 1924-74, dirigido por al prof. Bernardino Bravo Lira, Factultad de Derecho Universidad de Chile. 
si toda la estructura juridica, economica, financie:a y política del Estado, si toda la legislación social que ha satisfecho las ansias de justicia de las clases populares reposa hoy día sobre la base de los decretos leyes, ratificados, en gran parte, de una manera directa o indirecta, por el Poder Legislativo es vano intento pretender de los actuales Ministros de la Corte Suprema que quieran afrontar la responsabilidad de sumir pais en el caos que significaría el desconocimiento de esa legislación sobre la cual descansan instituciones como el Banco Central, los Bancos Comerciales e Hipotecarios, las Cajas de Previsión, etc....". Y, como si esto fuera poco, agregaba todavia: "Ia Carta Política, el Protocolo de Washington, la elección del actual Congreso y del Presidente, deben su existencia a la eficacia reconocida de los decretos leyes" 30 .

De los decretos con fuerza de ley puede decirse algo semejante. Por las materias que regelan superan en importancia a la legislación parkmentaria. Además, se trata con mucha fiecuencia, de leyes privilegio, pues se refieren a determinidas instituciones o grupos dentro de la pobiación $* 0$.

Finalmente, en cuanto a-la legislación exorada, esto es, dictada a instancias de los propios interesados, es notorio cómo desde 1925, en que los empleados particulares obtuvieron un estatuto especial, los gremios y entidades no luchan por la ley, sino por su leyt1.

Esta última expresión nos muestra que la legislación diferenciada por sectores y actividades, entidades o grupos, constituye también una manera de brindar seguridad jurídica, tal vez más apreciada por sus beneficiarios que ninguna de las anteriores. La fuerza con que se la defiende recuerda el apego que en otros tiempos tuvieron los distintos grupos de población a sus fueros.

$$
\text { VII. } \operatorname{coN} \text { O I. U S I } 6 \mathrm{~N}
$$

Los profesionales del derecho han reaccionado en general en forma hostil frente a la ley-privilegio. Ya en 1934 Pedro Lira denunciós su

* Corte Suprema, Oficio a la Canara de Dipulados 27 junio de 1933. respuesta a la acusación constitucional contra los Ministros y el Fiscal de la Corte Suprema, en Cámara de viputados, Boletín de sesiones ordinarias, Santiago 1933,940 ss. La cita 941-42.

*Terrer Puig, op. cit. (nota 38).

aSobre este punto. Bravo Lira, ip. cit. (nota 23) esp. 90, 165 y 174 ss. 
avance como una crisis del (lerechos2, lo que otros autores reiteraron en las décadas siguientes ${ }^{43}$. Tal parece ser el sentir dominante hasta ahora.

Pero no es tan claro que se trate de algo negativo. Más bien que ante una crisis del derecho, nos encontramos ante una crisis del derecho codificado44. A la legalidad uniforme de la codificación sucede una legalidad diferenciada de la ley-privilegio, mediante la cual es posible considerar la real diversidad de situaciones existentes den. tro de la población. Esta es su gran ventaja, sin desconocer que puede abusarse de ella para favorecer a sectores o grupos que no lo necesitan.

A pesar de estos inconvenientes y de la falta de sistematización de que adolece, la nueva legislación diferenciada es superior a lá antigua legislación uniforme de la codificación, por las posibilidades que abre para una verdadera y efjcaz renovación del derecho. I a clave de esta renovación no está en dar a todos lo mismo, como se éntendió en la época de la codificación. sino en algo mucho más complejo y matizado, como es dar a cadn uno lo suyo, lo cual no es posible. con una legislación uniforme y en cambio, st to es con una legislación diferenciada.

A manera de conclusión. cabe ołservar que esta legalidad diferenciada de nuestro tiempo, no tiene el carácter regulador que tuvieron la legalidad gubernativa, la legalidad estatal o la legalidad mandato uniforme. En este sentido, la ley-privilegio representa una especie de renacer dei derecho foral, que en su tiempo fue la expresion máxi. ma de la seguridad juridica.

"Lira Urquiela, Pedro, La crisis del derecha (1934), en Temas Universilarios, Santiago. 1945, 77 ss. El mismo, La necesidad de refundir y mo. dernizar nuestra legislación, Santiago. 1958

"Novoa Monreal, Eduardo, La crisis del Sistema Legal Chileno, en Revista de Derecho, Jurisprudencia y Ciencias Sociales 62, Santiago. I965. Velasco Letelier, Eugenio, El Derecho y los cambios sociales, Santiago. 1968.

*Bravo Lira, Bernardino, La positivación del Derecho, en Revista de Derecho, Jurisprudencia y Ciencias Sociales 62 (Santiago) 1965; Salvat Monguillot, Manuel, Necesidad de la perspectiva histórica en los Estudios de Derecho, en Anales de la Facultad de Ciencias Juridicas y Sociales, Universidad de Chile 7 (Santiago) 1967. 